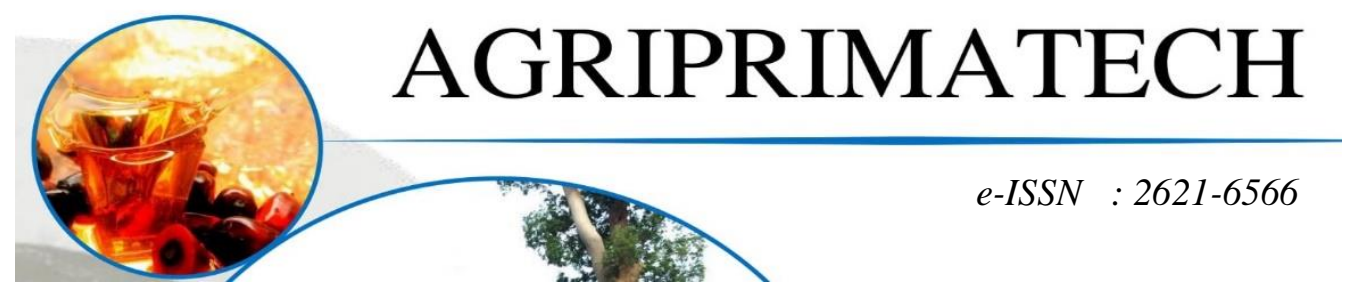

\title{
EFEKTIVITAS DAN DAMPAK PROGRAM BANTUAN LANGSUNG BENIH UNGGUL JAGUNG HIBRIDA TERHADAP PENDAPATAN PETANI DI KECAMATAN GUNUNG MALIGAS KABUPATEN SIMALUNGUN
}

\author{
MUSTAFA GINTING ${ }^{1}$, HOTMAN TUAH PURBA ${ }^{2}$ MUHAMMAD SULTAN \\ PRADINSYAH ${ }^{3}$ \\ 1,2Dosen Program Studi Agribisnis Fakultas Pertanian Universitas Simalungun \\ ${ }^{3}$ Mahasiswa Program Studi Agribisnis Fakultas Pertanian Universitas Simalungun \\ Email: Mustafaginting@yahoo.com
}

\begin{abstract}
ABSTRAK
Efektivitas Program BLBU Jagung Hibrida di Kecamatan Gunung Maligas Kabupaten Simalungun didapatkan hasil bahwa program tersebut terlaksana dengan efektif sesuai dengan prosedur pedoman pelaksanaan BLBU, program tersebut terlaksana tepat sasaran, tepat waktu, tepat jumlah, dan tepat bentuk. Danhasil uji paired sample t-test yang menunjukkan nilai sig (2-tailed) sebesar 0,000 yang lebih kecil dari 0,05 , serta nilai rata-rata pendapatan petani sesudah menerima program sebesar Rp.1,700,554.35yang lebih besar dari nilai rata-rata sebelum menerima program sebesar Rp.1,103,544.09 dengan selisih sebesar Rp.597,010.25.
\end{abstract}

Kata Kunci : Program, Bantuan, Benih, Jagung, Hibrida

\section{PENDAHULUAN}

Sektor pertanian memiliki multifungsi yang mencakup aspek ketahan pangan, peningkatan kesejahteraan petani, pengentasan kemiskinan, dan menjaga kelestarian lingkungan.Untuk kesengsaraan mengantisipasi harga faktor - faktor produksi pertanian pemerintah mencanangkan program khusus untuk mengatasi masalah tersebut.

Program tersebut adalah Program Bantuan Langsung Benih Unggul (BLBU).Bahwa untuk mendukung upaya peningkatan produktifitas/ produksi padi, jagung dan kedelai serta meringankan beban petani.
Program ini diperkenalkan tahun 2007 dan untuk menyediakan petani dengan benih bersertifikasi dengan gratis (padi, jagung, dan kedelai non hibrida dan hibrida). (Kementan Permentan No. 72/2007)(Perperes No.11/2011).

Program Bantuan Langsung Benih Unggul ini merupakan program yang sudah berjalan dari tahun anggaran 2009 sampai dengan sekarang. Program Bantuan Langsung Benih Unggul ini bertujuan untuk : 1) meningkatkan ketahanan pangan nasional, khususnya padi, jagung, dan kedelai; 2) meningkatkan penggunaan benih bermutu varietas unggul; 3) meningkatkan produktivitas dan produksi padi, jagung, dan kedelai. 
Sasaran yang ingin dicapai dari program ini adalah: 1) meningkatnya ketahanan pangan nasional, khususnya padi, jagung, dan kedelai; 2) meningkatnya penggunaan benih bermutu varietas unggul ; dan 3) meningkatnya produktivitas dan produksi padi, jagung, dan kedelai (Kementerian Pertanian, 2011).

Kepala Bidang Tanaman Pangan Dinas Tanaman Pangan dan Hortikultura Sumatera Utara, Juwaini .SP. MMA, mengatakan Sumatera Utara merupakan salah satu provinsi penerima BLBU Jagung Hibrida di Indonesia dari APBN Tahun 2019.Yang dialokasikan untuk ditanam di areal seluas 28.412,5 $\mathrm{Ha}$ dengan jumlah benih mencapai $346.755 \mathrm{Kg}$ dan bantuan tersebut dibagikan ke 24 Kabupaten/Kota di Sumatera Utara.Dan Kabupaten Simalungun merupakan salah satu penerima Program Bantuan Langsung Benih Unggul Jagung Hibrida dari 24 Kabupaten/Kota di Sumatera Utara.

Kadis Pertanian Kabupaten Simalungun, Jan Posman Purba menyebutkan bahwa terdapat 178 poktan di Kabupaten Simalungun yang menerima bantuan dari pemerintah pusat untuk luas lahan $2.743 \mathrm{Ha}$. Yang mana 178 poktan tersebut terdapat di 13 Kecamatan di Kabupaten Simalungun yaitu, Kecamatan Pematang Sidamanik, Kecamatan Purba, Kecamatan Dolog Masagal, Kecamatan Raya, Kecamatan Jorlang Hataran, Kecamatan Dolok Panribuan, Kecamatan Bandar Masilam, Kecamatan Raya Kahean, Kecamatan Sidamanik, Kecamatan Tanah Jawa, Kecamatan Pematang Silimakuta, Kecamatan Jawa Maraja Bah Jambi, dan Kecamatan Gunung Maligas. Adapun jenis benih jagung yang diterima petani yaitu jagung hibrida jenis BISI 228.

Kecamatan Gunung Maligas merupakan salah satu kecamatan yang menerima alokasi BLBU Jagung Hibrida di Kabupaten Simalungun. Dengan begitu diperlukan pengukuran bagaimana ke efektifan program tersebut sesuai atau tidak dengan yang diharapkan oleh pemerintah dan bagaimana dampaknya terhadap pendapatan petani.

\section{METODE PENELITIAN}

Penelitian ini dilaksanakan di Kecamatan Gunung Maligas Kabupaten Simalungun berdasarkan pertimbangan bahwa sebagian besar penduduknya bermata pencaharian sebagai petani dan Kecamatan Gunung Maligas merupakan salah satu daerah penerima BLBU jagung hibrida di Kabupaten Simalungun. Penelitian ini dilakukan pada bulan Februari - Maret 2020, dengan jumlah responden sebanyak 30 orang.

Metode pengumpulan data di penelitian ini terdiri atas data primer dan data sekunder. Dalam penelitian ini data primer di peroleh dari hasil wawancara langsung responden di Kecamatan Gunung Maligas dengan menggunakan daftar pertanyaan atau kuesioner yang telah dipersiapkan terlebih dahulu. Sedangkan data sekunder diperoleh dari instansi-instansi terkait seperti: Badan Pusat Statistik, Dinas Pertanian, literatur dan sumber lainnya.

Analisis data diambil melalui teknik analisis statistik deskriptif sederhana dengan melihat persentase pernyataan responden tentang efektivitas program dalam variabel input, proses, dan output. Dan penelitian ini menggunakan uji normalitas data dan uji beda rata-rata sampel berpasangan sebagai berikut:

\section{$>$ Uji normalitas}

Data untuk mendeteksi normalitas data yang dilakukan dengan menggunakan uji statistik kolmogorof smirnov.

Dengan syarat keputusan:

Ho: data terdistribusi secara normal.

$\mathrm{Ha}$ : data tidak terdistribusi secara normal.

-Jika nilai probabilitas $<0,05$ maka Ho ditolak (data tidak terdistribusi secara normal). 
-Jika nilai probabilitas $>0,05$ maka Ho diterima (data terdistribusi secara normal).

-Jika data berdistribusi secara normal maka analisis data dilanjut menggunakan uji Paired T Test.

\section{> Uji Beda Dua Rata-rata Sampel Berpasangan \\ Mengetahui adanya dampak} pendapatan petani yang masuk dalam anggota penerima bantuan melalui Program BLBU Jagung Hibrida pada saat sebelum dan sesudah terlaksananya Program BLBU Jagung Hibrida.

Pengujian ini digunakan untuk mengkaji keefektifan perlakuan, ditandai adanya perbedaan pendapatan petani.

\section{HASIL DAN PEMBAHASAN}

\section{Efektivitas Program Bantuan Langsung Benih Unggul Jagung Hibrida}

Berdasarkan hasil wawancara peneliti dengan petani penerima program BLBU Jagung Hibrida tentang efektivitas program BLBU Jagung Hibrida menggunakan beberapa indikator menurut (Pedoman Pelaksanaan BLBU, 2012) yaitu, tepat sasaran, tepat waktu, tepat jumlah, dan tepat bentuk, yaitu:

\section{Tepat Sasaran}

Berdasarkan data yang didapat peneliti dari UPT BP3 Kecamatan Gunung Maligas dan wawancara yang dilakukan peneliti terhadap responden, diketahui kriteria petani penerima bantuan benih jagung hibrida sesuai dengan kriteria penerima bantuan jagung hibrida yang ditetapkan pemerintah seperti petani yang menerima bantuan tergabung dalam Kelompok Tani/Gabungan Kelompok Tani dan sudah tercatat pada Surat Keputusan (SK) Bupati/Walikota atau diusulkan oleh Kepala Unit Kerja terkait. Dengan begitu
Program BLBU Jagung Hibrida di Kecamatan Gunung Maligas Tepat Sasaran dan efektif dalam hal lokasi dan penerima bantuan

\section{Tepat Waktu}

Berdasarkan hasil penelitian yang dilakukan peneliti diketahui pelaksanaan bantuan langsung benih unggul jagung hibrida di Kecamatan Gunung Maligas yang terealisasi pada tahun 2019 dan terlaksana kegiatan penyalurannya dan kegiatan penanamannya tepat waktu, yang mana penyaluran bantuan benih unggul jagung hibrida dilakukan secara bertahap pada bulan April tahun 2019 ke setiap nagori-nagori penerima bantuan tersebut. Dan penanaman benih jagung hibrida dilakukan sesuai jadwal yang ditetapkan oleh pemerintah yaitu 1 bulan setelah mendapat bantuan benih jagung hibrida yaitu pada bulan Mei tahun 2019.Sehingga dari segi tepat waktu pelaksanaan program BLBU Jagung Hibrida diketahui efektif dalam hal tepat waktu.

\section{Tepat Jumlah}

Dari hasil penelitian yang dilakukan peneliti diketahui pemberian bantuan langsung benih unggul jagung hibrida dilakukan berdasarkan luas areal tanam yang dimiliki petani yang mana setiap petani yang memiliki luas areal tanam 3-5 rante mendapatkan 1 bungkus benih jagung hibrida dengan berat perbungkusnya yaitu $5 \mathrm{~kg}$, sedangkan petani yang memiliki luas lahan 6-10 rante mendapatkan 2 bungkus atau $10 \mathrm{~kg}$, dan seterusnya. Yang mana jumlah benih yang diterima petani melebihi jumlah yang ditetapkan pemerintah yaitu $15 \mathrm{Kg} / \mathrm{Ha}$.Sehingga diketahui bahwa jumlah benih yang terima dengan jumlah yang tepat dan efektif. 


\section{$>$ Tepat Bentuk}

Berdasarkan wawancara peneliti terhadap petani/responden, petani menerima bantuan benih unggul jagung hibrida dengan keadaan baik atau tidak dalam keadaan rusak ataupun dalam bentuk jelek,dan tidak dalam masa kadaluwarsa, dengan begitu benih jagung hibrida yang diterima petani efektif dalam hal tepat bentuk.

Berdasarkan hasil dari 4 indikator pelaksanaan BLBU, diketahui bahwa prosedur pelaksanaan Program BLBU Jagung Hibrida di Kecamatan Gunung Maligas terlaksana dengan baik sesuai prosedur pelaksanaan BLBU dan berjalan secara efektif program tersebut.

\section{Dampak Program Bantuan Langsung Benih Unggul Jagung Hibrida Terhadap Pendapatan Petani}

Berdasarkan data yang diperoleh dari hasil penelitian, diketahui program bantuan langsung benih unggul jagung hibrida berdampak terhadap pendapatan petani yang mana terjadi perbedaan pendapatan yang signifikan sebelum dan sesudah menerima program bantuan langsung benih unggul jagung hibrida, yang mana dapat dilihat dari jumlah penggunaan biaya produksi, penerimaan, dan pendapatan yang dilihat dari sebelum menerima program dan sesudah menerima program, yaitu sebagai berikut:

\section{$>$ Biaya Produksi}

Dalam hal ini pendapatan petani dihitung berdasarkan seluruh biayabiaya yang dikeluarkan petani dalam membubidayakan jagung hibrida.Yang mana biaya-biaya yang dikeluarkan yaitu, biaya benih, biaya pupuk, biaya pestisida, dan biaya tenaga kerja yang digunakan selama budidaya jagung hibrida.

\section{$>$ Biaya benih}

Biaya yang dikeluarkan petani untuk membeli benih jagung hibrida perhektarenya yaitu Rp.2,087,438.5. dengan harga per $\mathrm{Kg}$ benih jagung hibrida yaitu Rp.83,497.54.

Sesudah menerima program petani tidak mengeluarkan biaya sama sekali untuk mengadakan benih jagung hibrida.

\section{Biaya pupuk}

Dari hasil penelitian diketahui harga pupuk NPK PHONSKA, TSP, dan NPK Mutiara mengalami peningkatan dan jumlah pupuk yang digunakan seperti Urea, NPK PHONSKA, SP36, ZA, dan SS mengalami peningkatan juga. Tetapi harga pupuk Urea mengalami peneurunan, dan jumlah pupuk yang digunakan yaitu TSP dan NPK Mutiara mengalami penurunan.

Sehingga terjadi penurunan biaya total penggunaan pupuk sesudah menggunakan BLBU Jagung Hibrida, yang mana sebelum menggunakan BLBU Jagung Hibrida yaitu sebesar Rp.1,058,794.66 per hektare menjadi Rp.1,055,640.41 per hektare.

\section{Biaya pestisida}

Hasil penelitian diketahui harga pestisida tidak mengalami peningkatan. Tetapi jumlah pestisida yang digunakan naik yang sebelum berjumlah 4.3 menjadi 4.9 .

Sehingga terjadi kenaikan biaya total penggunaan pestisida sesudah menggunakan BLBU Jagung Hibrida, yang mana sebelum menggunakan BLBU Jagung Hibrida yaitu sebesar Rp.163,152.56 per hektare menjadi Rp.186,410 per hektare.

\section{Biaya tenaga kerja}

Dalam penggunaan tenaga kerja dalam usahatani jagung hibrida di Kecamatan Gunung Maligas terbagi atas 2 jenis yaitu, Tenaga Kerja 
Mesin dan Tenaga Kerja Manusia (Hari Orang Kerja/HOK).

Dimana tenaga kerja mesin yaitu seperti pembajakan lahan menggunakan jetor dan pemipilan jagung menggunakan mesin pipil jagung. Dan dari hasil penelitian diketahui terjadi penurunan total biaya tenaga kerja yang digunakan sesudah menggunakan BLBU Jagung Hibrida, yang sebelumnya Rp.6,480,476 menjadi Rp.6,398,085 per hektare luas lahan.

\section{Penerimaan dan Pendapatan}

Hasil penelitian diketahui harga jual produksi jagung hibrida petani sebelum dan sesudah yaitu Rp.4,000/Kg Jagung kering yang mana harga tersebut diambil pada tahun 2019 yang mana penerimaan sebelum program BLBU yaitu Rp.13,866,960 dan sesudah program BLBU menjadi Rp. 14,765,360.

Dalam penelitian ini pendapatan petani sebelum dan sesudah menerima program BLBU Jagung Hibrida dihitung berdasarkan jumlah produksi perhektare dalam sekali masa program sebelum dan sesudah BLBU Jagung Hibrida tahun 2019.

Hasil penelitian diketahui adanya penurunan biaya total dan meningkatnya penerimaan usahatani, maka pendapatan usahatani jagung hibrida meningkat dari Rp.4,077,098.28 per hektare menjadi Rp.7,125,224.59 per hektare.

Peningkatan pendapatan ini mendorong kenaikan nilai R/C Ratio dari 1,42 menjadi 1,93. Yang mana nilai $\mathrm{R} / \mathrm{C}$ Ratio sebesar 1,93 memiliki pengertian bahwa apabila petani mengeluarkan biaya usahatani sebesar Rp. 1,- maka petani tersebut akan memperoleh penerimaan (revenue) sebesar Rp.1,93,-. Yang berarti usahatani jagung layak untuk diusahakan.

\section{Uji Normalitas Data}

Untuk mendeteksi normalitas data, penelitian ini menggunakan uji One Sample Kolmogorov Smirnov Test.Pengujian normalitas dilakukan dengan menilai 2-tailed significant dengan tingkat signifikansi $5 \%$.

Data dapat dikatakan berdistribusi normal apabila nilai Asymp. Sig. (2tailed) lebih besar dari 0,05 (Ghozali, 2011). Dengan demikian diperoleh hasil pengujian normalitas data pendapatan sebelum dan sesudah BLBU Jagung Hibrida yang dapat dilihat pada tabel 1 sebagai berikut:

\section{Tabel 1. Hasil Uji Normalitas Data Kolmogorov-Smirnov}

\begin{tabular}{|ll|r|r|r|}
\hline & & $\begin{array}{c}\text { Pendapatan Sebelum } \\
\text { BLBU }\end{array}$ & $\begin{array}{r}\text { Pendapatan Sesudah } \\
\text { BLBU }\end{array}$ & $\begin{array}{c}\text { Unstandardized } \\
\text { Residual }\end{array}$ \\
\hline $\mathrm{N}$ & & 30 & 30 & 30 \\
Normal & Mean & 1103544.0983 & 1700554.3533 & .0000000 \\
Parameters $^{\mathrm{a}, \mathrm{b}}$ & Std. & 874479.33526 & 1449538.64243 & 665317.84432758 \\
& Deviation & .158 & .271 & .127 \\
Most Extreme & Absolute & .158 & .271 & .096 \\
Differences & Positive & -.152 & -.150 & -.127 \\
& Negative & .158 & .271 & .127 \\
Test Statistic & & $.055^{\mathrm{c}}$ & $.000^{\mathrm{c}}$ & $.200^{\mathrm{cd}}$ \\
\hline
\end{tabular}

Sumber: Data Primer Diolah, 2020 
Berdasarkan hasil uji One Sample Kolmogorov Smirnov Test pada tabel 2 diatas diketahui bahwa nilai Asymp. Sig. (2-tailed) untuk sebelum program BLBU Jagung Hibrida adalah sebesar 0,055 dan untuk sesudah program BLBU Jagung Hibrida adalah sebesar 0,000.

Mana nilai sebelum program BLBU lebih besar dari nilai signifikansi 0,05 dan untuk nilai sesudah program BLBU lebih kecil dari nilai signifikansi 0,05 . Maka data yang tidak berdistribusi normal diresidualkan sehingga data menjadi berdistribusi normal yaitu dengan Asymp. Sig. (2-tailed) sebesar 0,200, yang mana signifikansi data lebih besar dari 0,05.

Maka dapat disimpulkan bahwa data pendapatan sebelum dan sesudah program BLBU Jagung Hibrida dapat dinyatakan berdistribusi normal.

Oleh karena itu, uji beda dapat dilakukan dengan menggunakan uji paired sample t-test.

\section{Uji Hipotesis}

Pengujian hipotesis dengan menggunakan uji paired sample t-test dilakukan untuk mengetahui apakah ada perbedaan rata-rata dua sampel yang berhubungan atau adakah perbedaan jika objek yang sama dalam perlakuan yang berbeda.

Untuk melihat kondisi sebelum dan sesudah. Suatu sampel dikatakan terdapat perbedaan sebelum dan sesudah jika nilai probabiltas $<0,05$. Sebaliknya jika probabilitasnya $>0,05$ maka tidak ada perbedaan sebelum dan sesudah program BLBU Jagung Hibrida.

Hasil Perhitungan uji paired sample $t$-test dapat disajikan pada tabel 2 berikut:

\section{Tabel 2. Hasil Uji Paired Sample T-Test}

\section{Paired Samples Test}

\begin{tabular}{|c|c|c|c|c|c|c|c|c|c|}
\hline & \multicolumn{5}{|c|}{ Paired Differences } & \multirow[b]{3}{*}{$\mathrm{t}$} & \multirow[b]{3}{*}{$d f$} & \multirow{3}{*}{$\begin{array}{l}\text { Sig. } \\
(2- \\
\text { taile } \\
\text { d) }\end{array}$} \\
\hline & & \multirow[b]{2}{*}{ Mean } & \multirow{2}{*}{$\begin{array}{c}\text { Std. } \\
\text { Deviation }\end{array}$} & \multirow{2}{*}{$\begin{array}{l}\text { Std. Error } \\
\text { Mean }\end{array}$} & \multicolumn{2}{|c|}{$\begin{array}{l}95 \% \text { Confidence Interval of } \\
\text { the Difference }\end{array}$} & & & \\
\hline & & & & & Lower & Upper & & & \\
\hline $\begin{array}{l}\mathrm{Pa} \\
\text { ir } \\
1\end{array}$ & $\begin{array}{l}\text { Pendapatan } \\
\text { Sebelum } \\
\text { BLBU - } \\
\text { Pendapatan } \\
\text { Sesudah } \\
\text { BLBU }\end{array}$ & $\begin{array}{r}1517010.25 \\
436\end{array}$ & $\begin{array}{r}1609189.92 \\
977\end{array}$ & $\begin{array}{r}293796.54 \\
128\end{array}$ & $\begin{array}{r}2117891.64 \\
934\end{array}$ & $\begin{array}{r}916128.859 \\
38\end{array}$ & $\begin{array}{r}5.16 \\
3\end{array}$ & 29 & .000 \\
\hline
\end{tabular}

Sumber: Data Primer Diolah, 2020

Hasil uji paired sample t-test pada tabel 2 diatas dapat dijelaskan sebagai berikut. Tingkat signifikansi dari uji ini adalah sebesar 5\%. Dasar pengambilan keputusan terhadap hipotesis yang diajukan adalah jika nilai sig. 2 (tailed) $<$ 0,05 maka $H_{0}$ ditolak begitu juga sebaliknya.

Dapat dilihat dari tabel, nilai sig. 2(tailed) adalah 0,000 dimana nilai ini lebih kecil dari 0,05 maka $\mathrm{H}_{\circ}$ ditolak dan $\mathrm{H}_{a}$ diterima. Maka diambil kesimpulan bahwa terdapat perbedaan signifikan terhadap peningkatan pendapatan petani sebelum dan sesudah program BLBU Jagung Hibrida.

\section{KESIMPULAN}

Berdasarkan hasil penelitian dan pembahasan maka diperoleh kesimpulan sebagai berikut:

Efektivitas Program Bantuan Langsung Benih Unggul Jagung Hibrida di Kecamatan Gunung Maligas Kabupaten Simalungun didapatkan hasil bahwa program tersebut terlaksana dengan efektif sesuai dengan prosedur pedoman pelaksanaan BLBU. 
Program tersebut terlaksana tepat sasaran, tepat waktu, tepat jumlah, dan tepat bentuk sehingga Program Bantuan Langsung Benih Unggul Jagung Hibrida di Kecamatan Gunung Maligas berjalan dengan efektif dilapangan.

Berdasarkan hipotesis yang dianalisis dengan menggunakan uji paired sample ttest dengan bantuan SPSS versi 25 .

Hal ini dapat dibuktikan dari hasil uji paired sample t-test yang menunjukkan nilai sig. (2-tailed) sebesar 0,000 yang lebih kecil dari 0,05 , serta nilai rata-rata pendapatan petani sesudah menerima program BLBU Jagung Hibrida sebesar Rp.1,700,554.35 yang lebih besar dari nilai rata-rata sebelum menerima program BLBU Jagung Hibrida sebesar Rp.1,103,544.09 dengan selisih rata-rata sebesar Rp.597,010.25, yang berarti terjadi dampak yang signifikan terhadap pendapatan petani.

\section{DAFTAR PUSTAKA}

Departemen Pertanian Nasional.2012.Tentang Pedoman Umum Bantuan Langsung Benih Unggul. Jakarta.

Direktorat Jenderal Tanaman Pangan. (2011). Petunjuk Teknis Bantuan Langsung Benih Unggul (Padi, Jagung, dan Kedelai) Tahun Anggaran 2011.Jakarta: Direktorat Jenderal Tanaman Pangan, Kementerian Pertania RI.

Ghozali, Imam. 2011. Aplikasi Analisis Multivariate dengan Program IBM

SPSS 19. Edisi Kelima. Semarang: Universitas Diponegoro 